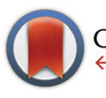

CrossMark \& click for updates

Cite this: Dalton Trans., 2016, 45 9460

Received 27th February 2016, Accepted 28th April 2016

DOI: 10.1039/c6dt00787b

www.rsc.org/dalton

\title{
The structure and in situ synthesis investigation of isomorphic mononuclear molecular metal phenylphosphonates $\uparrow$
}

\author{
Manuel Wilke, ${ }^{\mathrm{a}, \mathrm{b}}$ Ana Guilherme Buzanich, ${ }^{\mathrm{a}}$ Uwe Reinholz, ${ }^{\mathrm{a}}$ Klaus Rademann ${ }^{\mathrm{b}}$ and \\ Franziska Emmerling*a
}

\begin{abstract}
We describe a fast and effective synthesis for molecular metal phosphonates. Isomorphic compounds $\left[\mathrm{M}(\Perp)\left(\mathrm{HO}_{3} \mathrm{PPh}\right)_{2}\left(\mathrm{H}_{2} \mathrm{O}_{3} \mathrm{PPh}\right)_{2}\left(\mathrm{H}_{2} \mathrm{O}\right)_{2}\right]\left(\mathrm{M}=\mathrm{Mn}(\mathbf{1}), \mathrm{Co}(2), \mathrm{Ni}(3) ; \mathrm{Ph}=\mathrm{C}_{6} \mathrm{H}_{5}\right)$ were obtained by grinding. The complexes are mononuclear compounds containing neutral and monodeprotonated phenylphosphonic acid and water as ligands. The crystal structures were determined using powder X-ray diffraction (PXRD) data and validated by extended X-ray absorption fine structure (EXAFS) data. Combined synchrotron XRD measurements and Raman spectroscopy were conducted for investigating the reactions in situ. Based on these data, the intermediates were characterized and the formation mechanism was derived.
\end{abstract}

\section{Introduction}

Metal phosphonates are metal organic compounds containing phosphonic acid ligands. Depending on the coordination behaviour of the phosphonate ligands the structures are typically classified as coordination polymers (CP). ${ }^{1}$ Metal phosphonates with one-, two-, and three-dimensional structures are widely studied. ${ }^{2-7}$ Knowledge of molecular metal phosphonates (zerodimensional 0D) is scarce. Recently, the first comprehensive review was published by Goura $e t a .^{8}$ The research on molecular metal phosphonates is currently of increasing interest with respect to classical applications like catalysis, ${ }^{9}$ and the use of their outstanding magnetic properties..$^{10-12}$ Three synthetic strategies are known for synthesising molecular metal phosphonates inhibiting a potential polymerisation: (i) the use of ancillary ligands to block coordination sites, ${ }^{13,14}$ (ii) the use of phosphonate ligands with sterically demanding organic groups, ${ }^{13,15}$ and (iii) the strategy of cluster expansion. ${ }^{16}$

Milling reactions are a favourable method for synthesising metal phosphonates with one- and two-dimensional struc-

\footnotetext{
${ }^{a}$ Federal Institute for Materials Research and Testing (BAM), Richard-Willstaetter-Str. 11, 12489 Berlin, Germany. E-mail: franziska.emmerling@bam.de;

Fax: +49-30-8104-7-1133; Tel: +49-30-8104-1133

${ }^{b}$ Department of Chemistry, Humboldt-Universität zu Berlin, Brook-Taylor-Strasse 2, 12489 Berlin, Germany

$\dagger$ Electronic supplementary information (ESI) available: Selected bond lengths, angles and hydrogen bonds for 1, 2, and 3, PXRD patterns of the starting materials and compounds 1-3, enlarged 2D plots and Raman measurements of the in situ investigations of the syntheses of compounds 1-3, Raman spectra of the pure compounds 1-3 from the lab syntheses, phenylphosphonic acid and the empty perspex jar. CCDC 1453152-1453154. For ESI and crystallographic data in CIF or other electronic format see DOI: 10.1039/C6DT00787B
}

tures. This could be shown from previous work. ${ }^{17,18}$ Mechanochemistry enables the facile formation of compounds with monodeprotonated or neutral phosphonic acid as the ligand. To shed light on this method and unravel the underlying reaction mechanisms, in situ investigations were developed using X-ray diffraction, ${ }^{19}$ Raman spectroscopy ${ }^{20}$ and a combination of both the methods. ${ }^{17}$

Here, we present the mechanochemical syntheses of isomorphic molecular metal phosphonates $\left[\mathrm{M}(\mathrm{II})\left(\mathrm{HO}_{3} \mathrm{PPh}\right)_{2^{-}}\right.$ $\left.\left(\mathrm{H}_{2} \mathrm{O}_{3} \mathrm{PPh}\right)_{2}\left(\mathrm{H}_{2} \mathrm{O}\right)_{2}\right]\left(\mathrm{M}=\mathrm{Mn}(1)\right.$, $\left.\mathrm{Co}(2), \mathrm{Ni}(3) ; \mathrm{Ph}=\mathrm{C}_{6} \mathrm{H}_{5}\right)$. To our knowledge this is the first description of a mechanochemical preparation of $0 \mathrm{D}$ molecular metal phosphonates. The complexes are mononuclear and contain neutral and monodeprotonated phenylphosphonic acid and water as ligands. The structures of all three compounds were determined from the powder X-ray diffraction (PXRD) data and validated by EXAFS measurements. The syntheses were investigated in situ using combined synchrotron X-ray diffraction and Raman spectroscopy. Based on these data a reaction mechanism could be proposed.

\section{Experimental section}

\subsection{Chemicals}

The following chemicals were used: manganese(II) acetate tetrahydrate (purum p.a., Fluka, Switzerland), cobalt(II) acetate tetrahydrate ( $\geq 98 \%$, Carl Roth, Germany), nickel(II) acetate tetrahydrate (98+\%, Alfa Aesar, USA) and phenylphosphonic acid (98\%, Acros Organics, USA). All chemicals were used without further purification. 


\subsection{Synthesis of $\left[\mathrm{M}(\mathrm{II})\left(\mathrm{HO}_{3} \mathrm{PPh}\right)_{2}\left(\mathrm{H}_{2} \mathrm{O}_{3} \mathrm{PPh}\right)_{2}\left(\mathrm{H}_{2} \mathrm{O}\right)_{2}\right]$} (M = Mn (1), Co (2), Ni (3))

The synthesis was performed in a vibration ball mill Pulverisette 23 (Fritsch, Germany). In a stainless steel vessel the respective metal acetate tetrahydrate and phenylphosphonic acid were added together in a molar ratio of $1: 4$ and a total load of $1 \mathrm{~g}$. Two stainless steel balls (10 mm, $4 \mathrm{~g}$ ) were added and the mixture was ground at $50 \mathrm{~Hz}$ for $15 \mathrm{~min}$. A damp powder was obtained and dried in air. The colour of the powder was white for $\mathrm{M}=\mathrm{Mn}$ (1), lilac for Co (2), and yellow for $\mathrm{Ni}$ (3). CHN analysis (calculated value in brackets): (1) C: $39.87 \%$ (39.76\%), H: $4.11 \%$ (4.17\%), N: $0.13 \%(0 \%),(2)$ C: $39.77 \%$ (39.74\%), H: 4.09\% (4.17\%), N: 0.13\% (0\%), (3) C: $39.60 \%$ (39.96\%), H: $4.12 \%$ (4.19\%), N: $0.21 \%$ (0\%).

The syntheses were repeated as LAG (liquid assisted grinding) syntheses which had no effect on the quality of the data. In the case of (3) the LAG synthesis with water was always reproducible, whereas the dry synthesis leads occasionally to a mixture of (3) and an unknown phase, represented by two strong reflections at $8.4^{\circ}$ and 9.0 20. CCDC 1453153 (1), CCDC 1453152 (2), and CCDC 1453154 (3) contain the supplementary crystallographic data for these structures.

\subsection{Analytical techniques}

Powder X-ray diffraction (PXRD) data for structure solutions for 1 and 2 were collected using synchrotron XRD. The measurements were performed at the MS-Powder beamline (SLS, PSI, Switzerland) in transmission geometry. The powder patterns were collected at a wavelength of $\lambda=1.000 \AA$ with an exposure time of $30 \mathrm{~s}$. The data were recorded on a solid-state silicon microstrip detector (MYTHEN, SLS, PSI, Switzerland). In the laboratory, PXRD measurements were performed in transmission geometry in the $2 \theta$ range from $4^{\circ}$ to $60^{\circ}$ with a step size of $0.009^{\circ}$ using $\operatorname{CuK}_{\alpha 1}(\lambda=1.54056 \AA)$ radiation. The patterns were collected on a diffractometer (D8 Discover, Bruker AXS, Germany) equipped with a LYNXEYE detector and a Johansson monochromator in the incident beam. For structure solution of 3 the measured time per step was $33 \mathrm{~s}$.

The PXRD data were indexed using the program N-TREOR09 implemented in the EXPO2014 software. ${ }^{21}$ The structure of 1 was solved $a b$ initio using the RBM, COVMAP and Rietveld routine implemented in EXPO2014 after a default run. The structures of 2 and 3 were solved using the simulated annealing routine implemented in EXPO2014 with the structure motif found for $\mathbf{1}$. For $\mathbf{2}$ and $\mathbf{3}$ minor adaptations of the structure were performed in PowderCell to avoid short O-Odistances. $^{22}$ For 2 the Co-O1 bond was elongated from $2.151 \AA$ to $2.178 \AA$. For 3 the $\mathrm{P} 2$ phosphonate group was rotated $5^{\circ}$ around the $\mathrm{P} 2-\mathrm{C} 7$ axis. The final Rietveld refinements were conducted with TOPAS. ${ }^{23}$

The EXAFS (extended X-ray absorption fine structure) measurements were performed at the BAMline (Bessy-II, Helmholtz-Zentrum Berlin, Germany). ${ }^{24}$ The beam was monochromatised using a double-crystal monochromator (DCM). The size of the beam spot was $4 \mathrm{~mm} \times 1 \mathrm{~mm}$. The measure- ments were performed at the respective $\mathrm{K}$ edge (Mn: $6536 \mathrm{eV}$, Co: $7708 \mathrm{eV}$, Ni: $8330 \mathrm{eV}$ ) in transmission geometry. The excitation energy was varied from $6436 \mathrm{eV}$ to $7281 \mathrm{eV}$ for $\mathrm{Mn}$, from $7606 \mathrm{eV}$ to $8451 \mathrm{eV}$ for Co, and from $8230 \mathrm{eV}$ to $9075 \mathrm{eV}$ for Ni. The energy step width was $0.5 \mathrm{eV}$ in the near-edge region and $0.04 \AA$ for the $k$-space in the EXAFS region. For the measurements the samples were mixed with boron nitride and fixed in plastic sample holders. EXAFS data were processed by using ATHENA and ARTEMIS. ${ }^{25}$ These GUI programs belong to the main package IFEFFIT (v. 1.2.11). The $\left[\mathrm{M}(\mathrm{II})\left(\mathrm{HO}_{3} \mathrm{PPh}\right)_{2}\left(\mathrm{H}_{2} \mathrm{O}_{3} \mathrm{PPh}\right)_{2}\left(\mathrm{H}_{2} \mathrm{O}\right)_{2}\right]$ phases were theoretically modelled and fitted to the measured spectra using ARTEMIS.

The CHN analyses were conducted with EURO EA equipment (HEKAtech GmbH, Germany).

The reactions were investigated in situ using combined synchrotron XRD and Raman spectroscopy. The experiments were performed at the $\mu$ Spot beamline (Bessy-II, HelmholtzZentrum Berlin, Germany). ${ }^{26}$ The setup was reported in detail previously. ${ }^{17}$ A vibration ball mill Pulverisette 23 (Fritsch, Germany) was used for the milling experiments. In a $10 \mathrm{~mL}$ custom-made Perspex vessel all compounds and two stainless steel balls (10 mm, $4 \mathrm{~g}$ ) were ground together. The experimental conditions were similar to those described for the syntheses. The XRD patterns were collected using a two dimensional MarMosaic CCD detector $(3072 \times 3072$ pixels and a point spread function width of $73 \mu \mathrm{m})$. The exposure time was $30 \mathrm{~s}$ per measurement with a delay time of 3-4 s between the two measurements. For processing the scattering images an algorithm of the computer program FIT2D was used. ${ }^{27}$ The transformation of the scattering vector $(q)$ to the diffraction angle $2 \theta$ for $\mathrm{CuK}_{\alpha 1}$ radiation allows a direct comparison with the results of the laboratory PXRD measurements. Raman spectroscopy measurements were conducted on a Raman RXN1 $1^{\mathrm{TM}}$ analyser (Kaiser Optical systems, France) with an excitation radiation at $785 \mathrm{~nm}$. The spectrometer is equipped with a CCD detector $(1024 \times 256$ pixels $)$ and a non-contact probe head (working distance: $6 \mathrm{~cm}$, spot size: $1 \mathrm{~mm}$ ). The spectra were recorded five times for $5 \mathrm{~s}$ and then collected. A new measurement was started every $30 \mathrm{~s}$.

\section{Results and discussion}

\subsection{Syntheses and structure}

Compounds 1-3 were synthesised within 15 min by neat grinding. No further cleaning step was needed. The PXRD patterns showed no reflection of the starting materials (Fig. S1-S3 $\dagger$ ). The PXRD pattern of 1 shows a weak reflection at $2 \theta=6.1^{\circ}$ which indicates the formation of $\mathrm{Mn}\left(\mathrm{O}_{3} \mathrm{PPh}\right) \cdot \mathrm{H}_{2} \mathrm{O}$ as a side product. Rietveld refinement including both structures results in an amount of approximately $1 \%$ of $\mathrm{Mn}\left(\mathrm{O}_{3} \mathrm{PPh}\right) \cdot \mathrm{H}_{2} \mathrm{O}$.

All crystal structures were determined from the PXRD data. The final Rietveld and difference plots are shown in Fig. 1. The crystallographic data are summarized in Table 1 . The diffraction patterns of the compounds are characterized by the 
a)

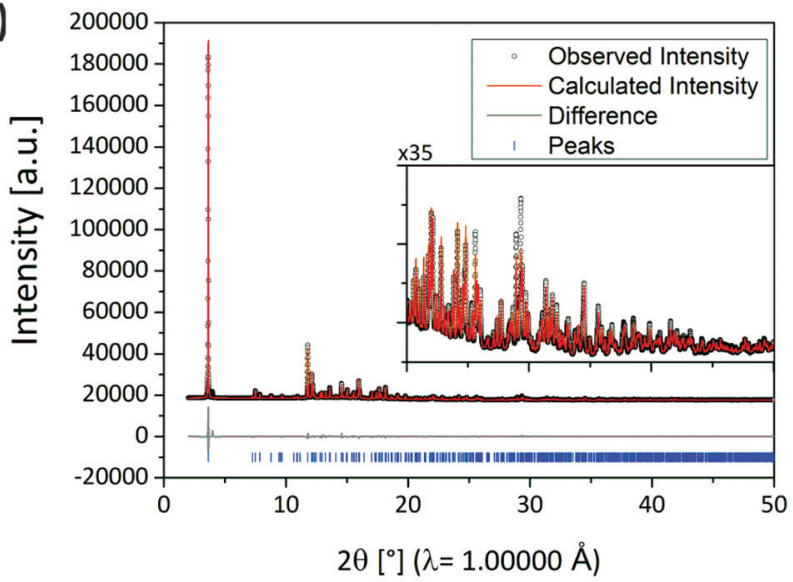

b)

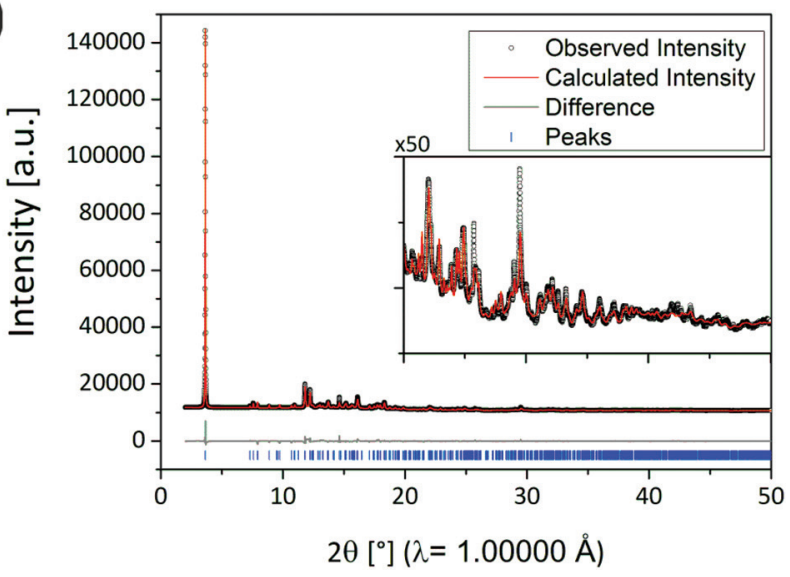

c)

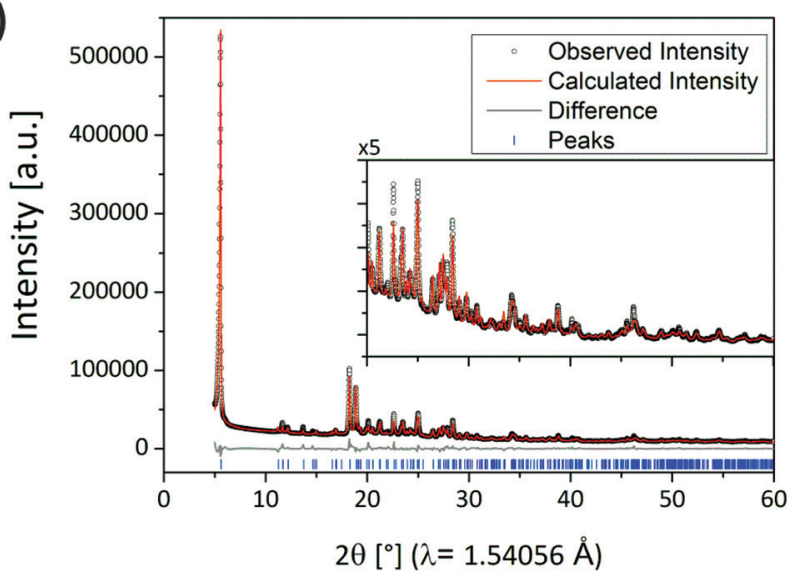

Fig. 1 Scattered X-ray intensity of (a) 1, (b) 2 and (c) 3 under ambient conditions as a function of the diffraction angle $2 \theta$. The observed pattern (circles), the best Rietveld fit profile (red line), the reflection positions (blue tick marks), and the difference curve (grey line) between observed and calculated profiles are shown. The wavelength is $\lambda=$ $1.00000 \AA$ for 1 and 2 and $\lambda=1.54056 \AA\left(\mathrm{CuK}_{\alpha 1}\right)$ for 3 . The $R$-values are $R_{\mathrm{p}}=3.62$ and $R_{\mathrm{wp}}=5.81$ for $1, R_{\mathrm{p}}=3.91$ and $R_{\mathrm{wp}}=6.04$ for 2 , and $R_{\mathrm{p}}=$ 4.19 and $R_{\mathrm{wp}}=6.00$ for $3 ; R_{\mathrm{p}}$ and $R_{\mathrm{wp}}$ refer to the Rietveld criteria of fit for the profile, weighted profile, and structure factor, as defined by Langford and Louer. ${ }^{28}$
Table 1 Crystal data and structure refinement parameters for the isomorphous metal phenylphosphonates $\left[\mathrm{M}(\mathrm{I})\left(\mathrm{HO}_{3} \mathrm{PPh}\right)_{2}\left(\mathrm{H}_{2} \mathrm{O}_{3} \mathrm{PPh}\right)_{2}\left(\mathrm{H}_{2} \mathrm{O}\right)_{2}\right]$ $(\mathrm{M}=\mathrm{Mn}(1), \mathrm{Co}(2), \mathrm{Ni}(3))$

\begin{tabular}{|c|c|c|c|}
\hline & 1 & 2 & 3 \\
\hline $\begin{array}{l}\text { Empirical } \\
\text { formula }\end{array}$ & $\mathrm{MnC}_{24} \mathrm{H}_{30} \mathrm{O}_{14} \mathrm{P}_{4}$ & $\mathrm{CoC}_{24} \mathrm{H}_{30} \mathrm{O}_{14} \mathrm{P}_{4}$ & $\mathrm{NiC}_{24} \mathrm{H}_{30} \mathrm{O}_{14} \mathrm{P}_{4}$ \\
\hline $\begin{array}{l}\text { Formula weight/ } \\
\mathrm{g} \mathrm{mol}^{-1}\end{array}$ & 721.32 & 725.32 & 725.08 \\
\hline Crystal system & Triclinic & Triclinic & Triclinic \\
\hline Space group & $P \overline{1}$ & $P \overline{1}$ & $P \overline{1}$ \\
\hline$a / \AA$ & $16.1474(2)$ & $16.0807(8)$ & $16.0587(9)$ \\
\hline$b / \AA$ & $7.72421(9)$ & $7.6539(3)$ & $7.6306(4)$ \\
\hline$c / \AA$ & $6.15467(8)$ & $6.1377(2)$ & $6.1169(3)$ \\
\hline$\alpha /{ }^{\circ}$ & $91.4505(6)$ & $91.772(3)$ & $91.768(3)$ \\
\hline$\beta /{ }^{\circ}$ & $98.9409(10)$ & $99.124(5)$ & $99.084(5)$ \\
\hline$\gamma /{ }^{\circ}$ & $97.7730(12)$ & $97.924(5)$ & $98.186(6)$ \\
\hline$V / \AA^{3}$ & $750.516(14)$ & $737.67(6)$ & $731.52(7)$ \\
\hline$Z$ & 1 & 1 & 1 \\
\hline$D_{\text {calc }} / \mathrm{g} \mathrm{cm}^{-3}$ & $1.59594(3)$ & $1.63272(12)$ & $1.64591(15)$ \\
\hline$R_{\mathrm{wp}}$ & 5.81 & 6.04 & 6.00 \\
\hline$R_{\text {Bragg }}$ & 2.168 & 2.630 & 2.961 \\
\hline GOF & 2.20 & 2.29 & 6.90 \\
\hline
\end{tabular}

strong (100) reflection at low angles $\left(d_{\text {approx }}=16.1 \AA\right)$ which can be used for an unambiguous phase identification.

In order to validate the coordination environment around the respective metal ions, EXAFS measurements were performed. The EXAFS data are shown in Fig. 2 in real space and the fit parameters are given in Table 2.

Fig. 3 shows the structure of 1 as an example. Selected bond lengths and angles are given in Tables S1 and S2. $\dagger$ The central metal atom is coordinated by six oxygen atoms in a distorted octahedron (Fig. 3a). For $\mathbf{1}$ this distortion is very low. The Mn-O-bonds range from 2.122(9)-2.295(9) $\AA$ and the $\mathrm{O}-\mathrm{Mn}-\mathrm{O}$-angles range from 85.8(4)-94.2(4) ${ }^{\circ}$. For 2 the distortion of the octahedron is more pronounced. The $\mathrm{Co}-\mathrm{O}$ bonds range from 2.0314(1)-2.3134(1) $\AA$ and the $\mathrm{O}-\mathrm{Co}-\mathrm{O}$ angles from 73.035(2)-106.965(2) $)^{\circ}$. In 3 the distortion of the octahedron is very similar to the one in 1 (Ni-O bonds: $2.1168(1)-2.3108(1)$ $\AA$; O-Ni-O angles: 87.393(1)-92.607(1) $\left.{ }^{\circ}\right)$. All the six coordinating oxygen atoms are from six different molecules; two from water molecules and four from phenylphosphonate ligands. All ligands are monodentate and show a 1.100-coordination mode according to the Harris notation. ${ }^{29}$ As a result, the structure consists of isolated metal complexes. There are two types of phenylphosphonate ligands, two neutral and two monodeprotonated phenylphosphonates. The isolated complexes are connected via strong and moderate hydrogen bonds (Table S4 $\dagger$ ). Additionally, there is one internal hydrogen bond in all three compounds between the water ligand $(\mathrm{O} 7)$ and the phenylphosphonate (O4) ligand. These connections result in a layered structure. The metal complexes form an inorganic layer while the phenyl rings point into the interlayer space. The phenyl rings connect the layers via van der Waals forces.

The comparison between the PXRD patterns of the products and the PXRD patterns of the starting materials (Fig. S1-S3†) show that the conversion is complete. $\mathrm{Mn}\left(\mathrm{O}_{3} \mathrm{PPh}\right) \cdot \mathrm{H}_{2} \mathrm{O}$ coexists as a side product of $\mathbf{1}$ in a small ratio most probably because it 

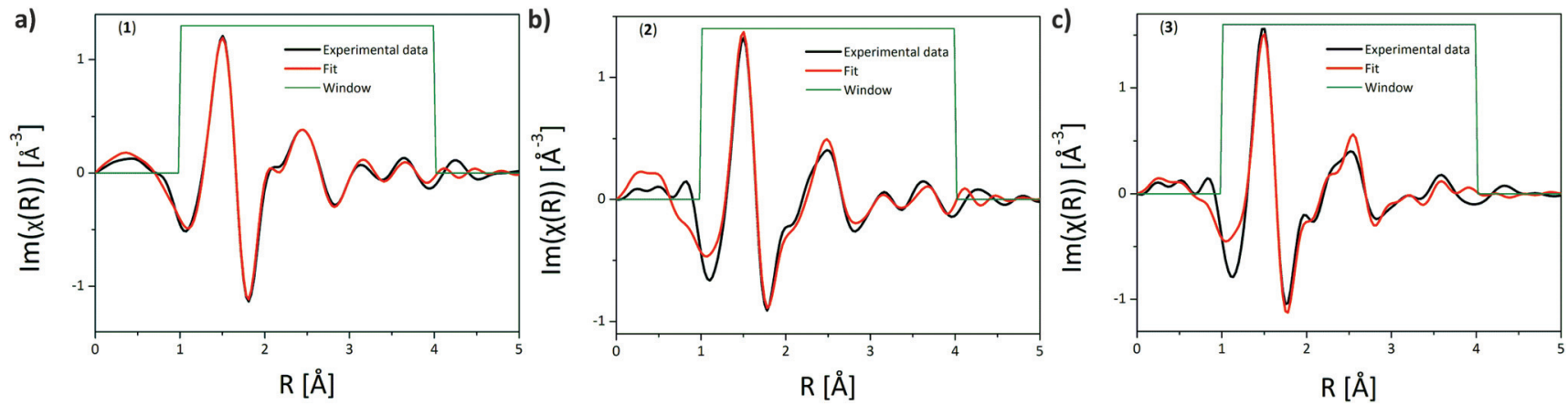

Fig. 2 (a) Mn K-edge EXAFS data shown in real space for compounds $\left[\mathrm{Mn}\left(\mathrm{HO}_{3} \mathrm{PPh}\right)_{2}\left(\mathrm{H}_{2} \mathrm{O}_{3} \mathrm{PPh}\right)_{2}\left(\mathrm{H}_{2} \mathrm{O}\right)_{2}\right](1) ; R=0.005$. (b) Co K-edge EXAFS data shown in real space of $\left[\mathrm{Co}\left(\mathrm{HO}_{3} \mathrm{PPh}\right)_{2}\left(\mathrm{H}_{2} \mathrm{O}_{3} \mathrm{PPh}\right)_{2}\left(\mathrm{H}_{2} \mathrm{O}\right)_{2}\right]$ (2); $R=0.027$. (c) $\mathrm{Ni} \mathrm{K}$-edge EXAFS data shown in real space of $\left[\mathrm{Ni}\left(\mathrm{HO}{ }_{3} \mathrm{PPh}\right)_{2}-\right.$ $\left.\left(\mathrm{H}_{2} \mathrm{O}_{3} \mathrm{PPh}\right)_{2}\left(\mathrm{H}_{2} \mathrm{O}\right)_{2}\right](3) ; R=0.052$. Experimental data: black, fit results: red, fit window: green.

Table 2 EXAFS fit parameters of 1,2 and 3. The root mean square error (RMSE) of 1 is $0.120 \AA$, of 2 is $0.370 \AA$, and of 3 is $0.132 \AA$

\begin{tabular}{lllll}
\hline Sample & Scattering path & $R_{\text {model }}[\AA]$ & $R_{\text {fit }}[\AA]$ & $R_{\text {diff }}^{2}[\AA]$ \\
\hline 1 & 2.12 & 2.03 & 0.0081 \\
& Mn1-O1 & 2.20 & 2.17 & 0.0009 \\
Mn1-O5 & 2.30 & 2.21 & 0.0081 \\
Mn1-O7 & 3.38 & 3.33 & 0.0025 \\
Mn1-P1 & 3.51 & 3.54 & 0.0009 \\
Mn1-P2 & 3.59 & 3.36 & 0.0529 \\
Mn1-O3 & 3.70 & 3.60 & 0.0100 \\
Mn1-O4 & 3.69 & 3.58 & 0.0121 \\
Mn1-O2 & 4.24 & 4.21 & 0.0009 \\
Mn1-O6 & 4.34 & 4.56 & 0.0484 \\
Mn1-O2 & 2.03 & 2.09 & 0.0036 \\
Co1-O7 & 2.18 & 2.09 & 0.0081 \\
Co1-O1 & 2.31 & 2.26 & 0.0025 \\
Co1-O5 & 3.30 & 3.38 & 0.0064 \\
Co1-P1 & 3.34 & 3.45 & 0.0121 \\
Co1-O3 & 3.48 & 3.52 & 0.0016 \\
Co1-P2 & 3.55 & 3.00 & 0.3025 \\
Co1-O4 & 3.61 & 4.58 & 0.9409 \\
Co1-O2 & 4.20 & 4.20 & 0.0000 \\
Co1-O6 & 4.29 & 4.59 & 0.0900 \\
Co1-O2 & 2.12 & 2.07 & 0.0025 \\
Ni1-O1 & 2.24 & 2.07 & 0.0289 \\
Ni1-O5 & 2.31 & 2.24 & 0.0049 \\
Ni1-O7 & 3.38 & 3.32 & 0.0036 \\
Ni1-P1 & 3.42 & 3.61 & 0.0361 \\
Ni1-P2 & 3.58 & 3.63 & 0.0025 \\
Ni1-O3 & 3.58 & 3.63 & 0.0025 \\
Ni1-O4 & 3.61 & 3.66 & 0.0025 \\
Ni1-O2 & 4.05 & 3.91 & 0.0169 \\
Ni1-O6 & 4.23 & 4.06 & 0.0289 \\
Ni1-O2 & & &
\end{tabular}

is the thermodynamically stable compound. This effect was observed earlier. ${ }^{18}$ The thermodynamic stability of metal organic frameworks can be derived from their density, expressed by the central atom per $\mathrm{nm}^{3}$ ratio. ${ }^{30}$ The higher the ratio, the more thermodynamically stable is the compound. For $\mathrm{Mn}\left(\mathrm{O}_{3} \mathrm{PPh}\right) \cdot \mathrm{H}_{2} \mathrm{O}$ the $\mathrm{Mn}$ per $\mathrm{nm}^{3}$ ratio is 4.92 . With 1.33 this value is much lower for $\mathbf{1}$. However, the compound is almost pure (99\%). b)
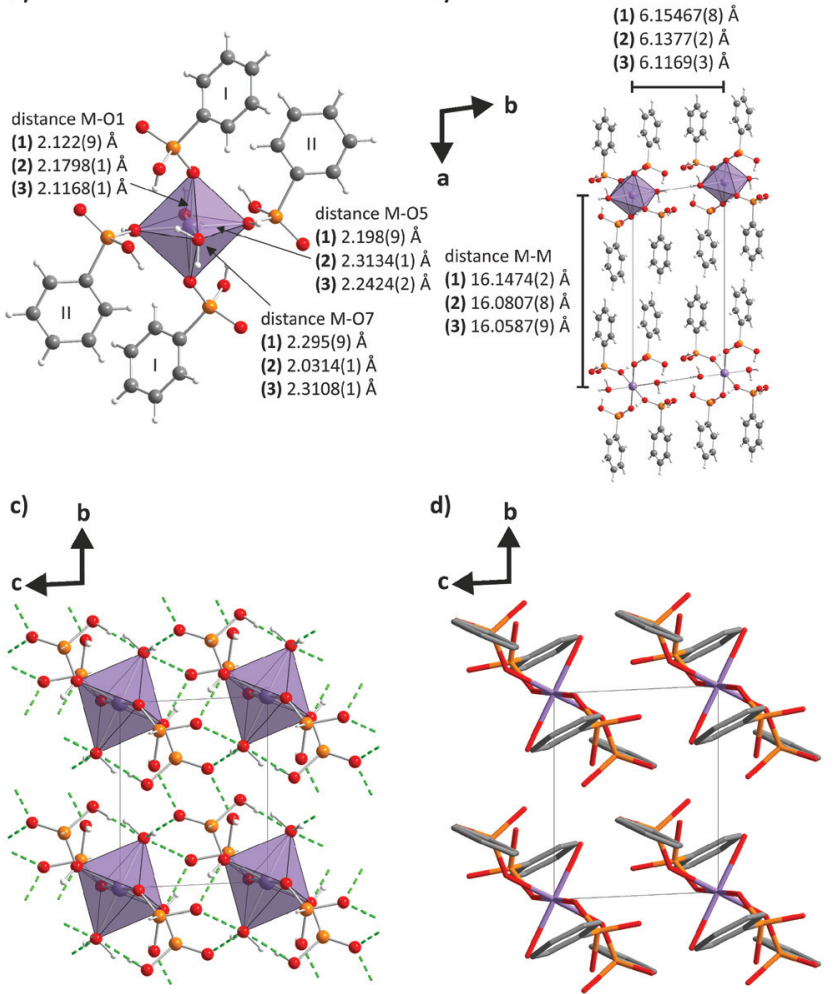

Fig. 3 Structure of 1 with respective values for the isomorphic compounds 2 and 3. (a) Coordination sphere of the metal ion. (b) Structure of 1 shown along the $c$-axis. (c) Structure of 1 shown along the a-axis illustrating the arrangement and connections via hydrogen bonds (green dashed lines) of the metal complexes. The phenyl rings are omitted for clarity. (d) Wireframe representation of the structure of 1 shown along the a-axis illustrating the arrangement of the phenyl rings. Hydrogen atoms are omitted for clarity. Purple: manganese, red: oxygen, orange: phosphorus, gray: carbon, light gray: hydrogen.

The reactions can be described with the following equation:

$$
\begin{aligned}
& \mathrm{M}(\mathrm{II})\left(\mathrm{H}_{3} \mathrm{CCO}_{2}\right)_{2} \cdot 4 \mathrm{H}_{2} \mathrm{O}+4 \mathrm{H}_{2} \mathrm{O}_{3} \mathrm{PC}_{6} \mathrm{H}_{5} \rightarrow \\
& {\left[\mathrm{M}(\mathrm{II})\left(\mathrm{HO}_{3} \mathrm{PC}_{6} \mathrm{H}_{5}\right)_{2}\left(\mathrm{H}_{2} \mathrm{O}_{3} \mathrm{PC}_{6} \mathrm{H}_{5}\right)_{2}\left(\mathrm{H}_{2} \mathrm{O}\right)_{2}\right]} \\
& +2 \mathrm{H}_{3} \mathrm{CCO}_{2} \mathrm{H}+2 \mathrm{H}_{2} \mathrm{O}
\end{aligned}
$$


During the reaction, acetic acid and water are released. The dry milling synthesis is liquid assisted by its side products and the product was always damp after milling.

The structure of $\mathbf{1}$ could be solved ab initio from the PXRD data. The structures of $\mathbf{2}$ and $\mathbf{3}$ were refined based on the structure model of compound $\mathbf{1}$. The accuracy of the received structures was validated by the EXAFS data. The first and second coordination spheres around the central metals are consistent with the structure determined by PXRD. The root mean square errors for the scattering path are $0.120 \AA$ for $1,0.370 \AA$ for 2 , and $0.132 \AA$ for 3 .

The metal to phosphonate ligand ratio of $1: 4$ in the compounds is very rare. Under mechanochemical conditions the reaction can be performed in such a way that the deprotonation of the acid can be kept low. Here, two phenylphosphonate ligands are monodeprotonated and two are neutral phenylphosphonic acids. The charge carrier can be estimated from the $\mathrm{P}-\mathrm{O}$ bond length and the coordination. Both phosphonate groups contain one long $\mathrm{P}-\mathrm{O}$ bond about $1.6 \AA$. This is a common bond length for non coordinating protonated oxygen. It can be concluded that $\mathrm{O} 3$ and $\mathrm{O} 4$ are protonated. There is one short bond between P2 and O6 (1.503(8) A for 1, 1.4647(1) $\AA$ for 2, 1.4630(1) $\AA$ for 3). It represents a P-O double bond. The second phosphonate group does not contain such a short $\mathrm{P}-\mathrm{O}$ bond. The $\mathrm{P} 1-\mathrm{O} 1$ and the $\mathrm{P} 1-\mathrm{O} 2$ bonds are similar in length of about $1.5 \AA$. The charge carrier is clearly located at the phosphonate group of $\mathrm{P} 1$. The charge is delocalised between $\mathrm{O} 1$ and $\mathrm{O} 2$. The third proton is located at $\mathrm{O} 5$, which is also coordinating to the metal centre. The P2-O5 bond lengths are 1.534(8) A for 1, 1.4982(1) A for 2 and 1.4940(1) A for 3.

The resulting structures are mononuclear molecular metal phosphonates. There are no covalent connections between the $\left[\mathrm{M}(\mathrm{II})\left(\mathrm{HO}_{3} \mathrm{PPh}\right)_{2}\left(\mathrm{H}_{2} \mathrm{O}_{3} \mathrm{PPh}\right)_{2}\left(\mathrm{H}_{2} \mathrm{O}\right)_{2}\right]$ units. The important directing factor is the ratio of the starting compounds. Mechanochemical reactions are highly controllable by varying the ratio of the starting materials. ${ }^{18,31-34}$ Polymerisation was inhibited due to the high number of ligands.

\subsection{Mechanistic in situ studies}

All syntheses were investigated in situ by combined synchrotron XRD and Raman spectroscopy. The time at $t=0 \mathrm{~s}$ in the $\mathrm{XRD}$ plots represent the mixture of the starting materials without milling. For the Raman spectra only the areas, where differences between the bands of the free phenylphosphonic acid and the coordinated phenyl phosphonate ligands are observable, are shown. The first spectra represent the empty perspex jar. The Raman spectra of the pure products from the lab syntheses, phenylphosphonic acid and the empty perspex jar are given in Fig. S7. $\uparrow$ The bands at about $3050 \mathrm{~cm}^{-1}$ are assigned as $\nu(\mathrm{CH})$ vibrations. Their change is most probably a result of the different arrangements of the phenyl rings in the products, as the complex Raman spectrum bands at lower values cannot be assigned.

Fig. 4a shows the $2 \mathrm{D}$ plot of the in situ investigation of the synthesis of 1 with synchrotron XRD. The synthesis consists of five phases. At $t=0 \mathrm{~s}$ phase 1 contains only reflections of the starting materials. The most intense reflections are the (100) reflection at $9.3^{\circ}$ for manganese(II) acetate tetrahydrate and the (211) reflection at $20.2^{\circ}$ for phenylphosphonic acid. $30 \mathrm{~s}$ after the milling started, an additional reflection at $5.9^{\circ}$ can be detected, representing an unknown phase (phase 2). In the next $30 \mathrm{~s}$ strong reflections of the final product and weaker reflections of $\mathrm{Mn}\left(\mathrm{O}_{3} \mathrm{PC}_{6} \mathrm{H}_{5}\right) \cdot \mathrm{H}_{2} \mathrm{O}$ were obtained (phase 3). The most intense reflections are the (100) reflection at $5.6^{\circ}$ and the (010) reflection at $6.1^{\circ}$, respectively. After $1.15 \mathrm{~min}$ the reflections of both starting materials vanish (start phase 4). In the following minutes, the reflections of the final product increase, while those of $\mathrm{Mn}\left(\mathrm{O}_{3} \mathrm{PC}_{6} \mathrm{H}_{5}\right) \cdot \mathrm{H}_{2} \mathrm{O}$ start to decrease. After 6 min these reflections are at their minimum and do not change anymore (start of phase 5). The corresponding Raman spectra are shown in Fig. 4b. After $30 \mathrm{~s}$ of milling, only bands of phenylphosphonic acid can be observed. $30 \mathrm{~s}$ later these bands decrease rapidly and the bands of the coordinated phenylphosphonate ligand appear. Over the next minute the bands of the free phenylphosphonic acid disappear and the intensity of the coordinated phenylphosphonate ligand bands increase. There are no further changes in the position of the bands until the end of the reaction.

The 2D plots of the in situ investigation of the synthesis of 2 with synchrotron XRD are depicted in Fig. 4c. At the beginning and $30 \mathrm{~s}$ after the start, only reflections for both starting materials can be detected (phase 1). The (011) reflection at $12.8^{\circ}$ is the most intense reflection for cobalt(II) acetate tetrahydrate. In the next measurement, the strong (100) reflection at $5.6^{\circ}$ indicates the formation of the final product (phase 2). After 2.15 min of milling, reflections of cobalt(II) acetate tetrahydrate vanish and the formation of $\mathrm{Co}\left(\mathrm{O}_{3} \mathrm{PC}_{6} \mathrm{H}_{5}\right) \cdot \mathrm{H}_{2} \mathrm{O}$ is verified by the strong (010) reflection at $6.1^{\circ}$ (start phase 3 ). This reflection remains for $90 \mathrm{~s}$. Afterwards reflections of the final product and phenylphosphonic acid can be detected up to 5 min of overall milling time (phase 4). In the next $10 \mathrm{~min}$ only reflections of the final product can be observed. Fig. $4 \mathrm{~d}$ shows the corresponding Raman spectra of the in situ investigation of this reaction. $30 \mathrm{~s}$ after the reaction starts only bands of the phenylphosphonic acid can be detected. One measurement later, small shoulders at the bands of phenylphosphonic acid indicate the formation of the final product in a small ratio. Over the next $4 \mathrm{~min}$ the intensities of the bands for the final product increase while those for phenylphosphonic acid decrease but with variability in their ratio. After $5.00 \mathrm{~min}$ of milling time only bands of the final product can be obtained. This does not change until the end of the reaction.

The in situ investigation of the synthesis of 3 with synchrotron XRD is represented as a $2 \mathrm{D}$ plot in Fig. 4e. From the beginning up to $2.45 \mathrm{~min}$ of milling time, only reflections of both starting materials can be detected (phase 1). For nickel(II) acetate tetrahydrate the $(011)$ reflection at $12.9^{\circ}$ is the most intense reflection. $30 \mathrm{~s}$ later the $(100)$ reflection at $5.6^{\circ}$ indicates the formation of the final product (phase 2). The existence of an unknown intermediate is proved by the two reflections at $7.9^{\circ}$ and $9.5^{\circ}$. The reflections of the starting materials vanish after 5.30 min of milling (start phase 3). $30 \mathrm{~s}$ 


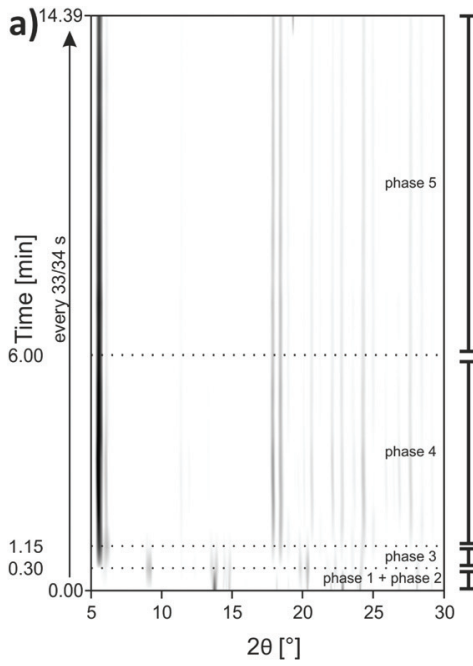

(1)
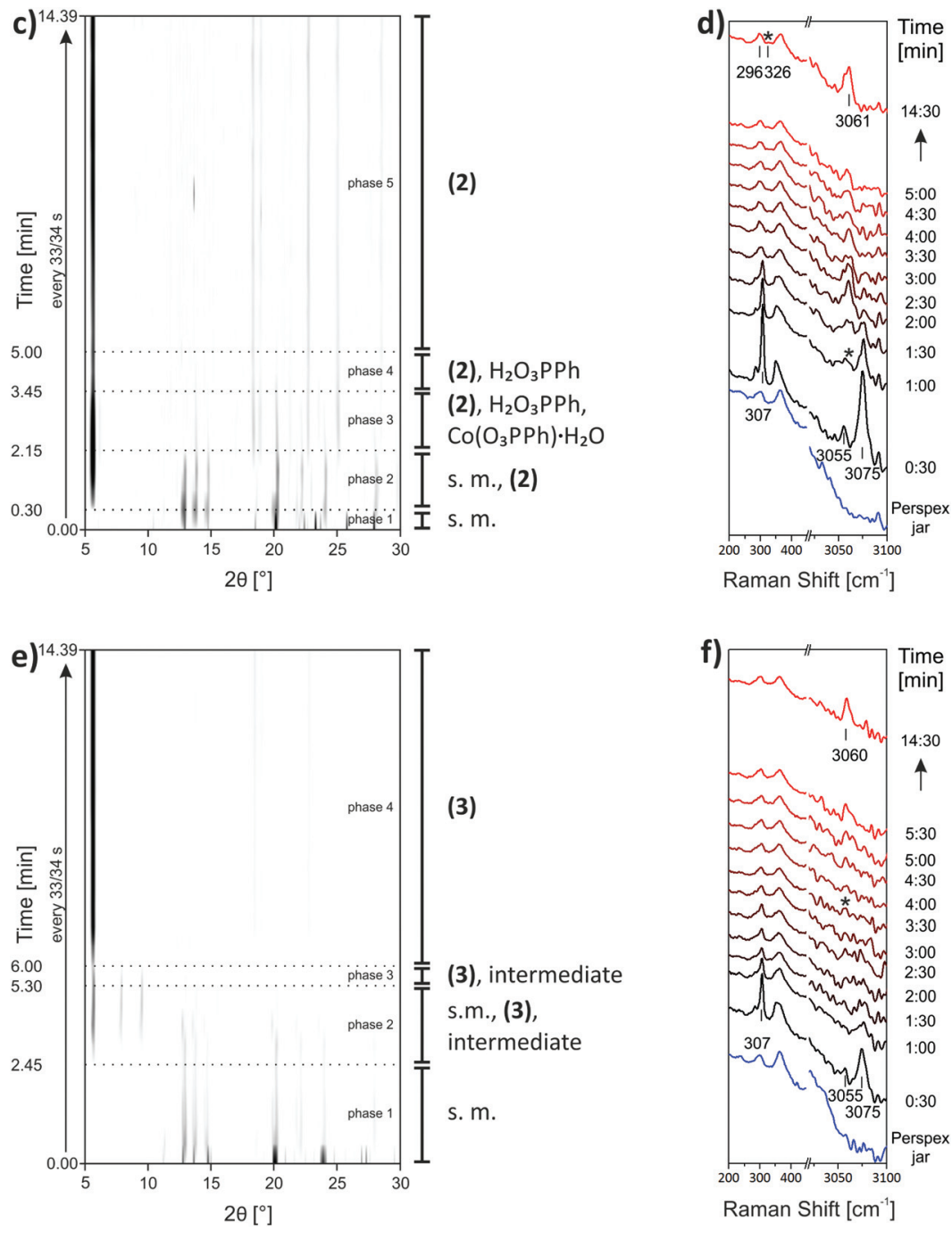

Fig. 4 2D plots of synchrotron XRD data with a description of the detected compounds and in situ Raman spectroscopy measurements for the syntheses of (a), (b) 1, (c), (d) 2 and (e), (f) 3; s.m. = starting materials. 
later the two reflections of the intermediate vanish too (phase 4). The intensity of the reflection at $5.6^{\circ}$ increase over the next minutes and more reflections of the final product appear but no other compounds can be detected until the end of the reaction. The corresponding Raman spectra are depicted in Fig. $4 \mathrm{f}$. After $30 \mathrm{~s}$ of milling time only bands for phenylphosphonic acid can be observed. In the next few minutes only weak bands of these starting materials can be detected. After $3.30 \mathrm{~min}$ a band attributed to the coordinated phenyl phosphonate at $3060 \mathrm{~cm}^{-1}$ appears. Over the next minute its intensity increases while the bands of phenylphosphonic acid vanish. There are no further changes from $5.30 \mathrm{~min}$ until the end of the reaction.

In the in situ investigation of the synthesis of 1 with synchrotron XRD $30 \mathrm{~s}$ after the start a reflection at $5.9^{\circ}$ can be obtained. This position is between the positions of the strong reflections of 1 and $\mathrm{Mn}\left(\mathrm{O}_{3} \mathrm{PPh}\right) \cdot \mathrm{H}_{2} \mathrm{O}\left(5.6^{\circ}\right.$ and $6.1^{\circ}$, respectively). $30 \mathrm{~s}$ later reflections of both compounds can be detected clearly. The reflections of the starting materials vanish fast but six minutes are needed until the reflections of $\mathrm{Mn}\left(\mathrm{O}_{3} \mathrm{PPh}\right) \cdot \mathrm{H}_{2} \mathrm{O}$ reach their minimum. As expected, since $\mathrm{Mn}\left(\mathrm{O}_{3} \mathrm{PPh}\right) \cdot \mathrm{H}_{2} \mathrm{O}$ was also a side product of the laboratory synthesis, they do not vanish. The effects of the thermodynamic stability were discussed before.

The respective 1:1 metal phenylphosphonate, $\mathrm{Co}\left(\mathrm{O}_{3} \mathrm{PPh}\right) \cdot \mathrm{H}_{2} \mathrm{O}$, also appears as an intermediate in the in situ investigation of 2 . The characteristic reflections can be detected $1.15 \mathrm{~min}$ after the formation of $\mathbf{1}$ and remain for only $90 \mathrm{~s}$. At the same time reflections of phenylphosphonic acid can be detected. $\mathrm{Co}\left(\mathrm{O}_{3} \mathrm{PPh}\right) \cdot \mathrm{H}_{2} \mathrm{O}$ forms and then it reacts with phenylphosphonic acid to 2. 2 was also formed as an intermediate in the mechanochemical synthesis of $\mathrm{Co}\left(\mathrm{O}_{3} \mathrm{PPh}\right) \cdot \mathrm{H}_{2} \mathrm{O} .^{17}$

In the in situ investigation of the synthesis of 3 with synchrotron XRD, no reflections of the $1: 1$ compound $\left(\mathrm{Ni}\left(\mathrm{O}_{3} \mathrm{PPh}\right) \cdot \mathrm{H}_{2} \mathrm{O}\right)$ can be detected. In contrast to the much faster syntheses of compound $\mathbf{1}$ and $\mathbf{2}$ the final product cannot be detected up to $2.45 \mathrm{~min}$. Simultaneously an unknown intermediate is formed, indicated by two reflections at $7.9^{\circ}$ and $9.5^{\circ}$. These two reflections appear more in mechanochemical synthesis with a metal salt and phenylphosphonic acid, for instance in the mechanochemical synthesis of $\mathrm{Co}\left(\mathrm{O}_{3} \mathrm{PPh}\right) \cdot \mathrm{H}_{2} \mathrm{O}$. This is most probably an isomorphic metal phenylphosphonate structure which is formed intermediately or a polymorphic crystal structure of phenylphosphonic acid itself.

In the in situ investigations with Raman spectroscopy a change from phenylphosphonic acid to coordinated phenylphosphonate ligands can be observed. No intermediates can be detected. The time scale of the reaction is similar to the time scale found with the synchrotron XRD.

In all syntheses the thermodynamically less stable product is formed in the end, even in those cases where the reflections of the more stable product are observable intermediately. This makes the molar ratio of the starting materials the main directing factor. The control of the product of mechanochemical reactions by varying the stoichiometric ratio is a known strategy. ${ }^{18,31-34}$ The interaction of both factors, the thermodynamic stability and the ratio of the starting material, leads to the obtained reaction paths. Reflections of one unknown intermediate could be detected and all other compounds could be identified. Also in the Raman measurements no other intermediates like mixed salts or amorphous phases are observable. As described the syntheses are liquid assisted by their side products. In liquid assisted grinding syntheses the diffusion rate is higher than in the dry ones. Based on these results, a diffusion mechanism is the most probable one. This mechanism is based on thorough stirring of very small solid particles. ${ }^{35}$ First, only the reflections of the starting materials can be detected. After reflections of the products and intermediates appear, their intensity increases over a certain time whereas the intensity of the reflections of the starting materials starts to decrease. The concurrent increase and decrease shows that the diffusion mechanism provides the best explanation for these straight-lined reaction pathways. The same behaviour is observed for the intermediate reflections. First their intensity increases and then it starts to decrease while the intensity of the reflections of the product increases.

\section{Conclusions}

A new technique for synthesising 0D mononuclear molecular metal phenylphosphonates is presented. With reaction times below $10 \mathrm{~min}$ the syntheses are unexpectedly fast and lead to the formation of pure products. The structures of the three complexes were determined and described. A diffusion mechanism was shown to be the most probable reaction mechanism based on in situ measurements (PXRD and Raman spectroscopy). The process described could be used for the synthesis of other molecular metal phosphonates. This provides new opportunities to develop multifunctional materials for applications related to the catalytic and magnetic properties. The synthesis is fast, facile, scalable, and environmentally friendly and has strong potential for industrial applications.

\section{Acknowledgements}

The authors are grateful for the funding received from the DFG program "Crystalline non-equilibrium compounds" (grant number Em198/3-2). The authors thank Dr Andrea Zehl and Jenny Odoj (Department of Chemistry, Humboldt-Universität zu Berlin) for CHN analysis measurements and the PSI for the opportunity to measure high resolution PXRD.

\section{References}

1 S. R. Batten, N. R. Champness, X. M. Chen, J. GarciaMartinez, S. Kitagawa, L. Ohrstrom, M. O’Keeffe, M. P. Suh and J. Reedijk, Pure Appl. Chem., 2013, 85, 1715-1724.

2 A. Clearfield, Curr. Opin. Solid State Mater. Sci., 1996, 1, 268-278. 
3 G. B. Hix, A. Turner, B. M. Kariuki, M. Tremayne and E. J. MacLean, J. Mater. Chem., 2002, 12, 3220-3227.

4 K. Maeda, Microporous Mesoporous Mater., 2004, 73, 47-55.

5 G. K. H. Shimizu, R. Vaidhyanathan and J. M. Taylor, Chem. Soc. Rev., 2009, 38, 1430-1449.

6 N. Stavgianoudaki, K. E. Papathanasiou, R. M. P. Colodrero, D. Choquesillo-Lazarte, J. M. GarciaRuiz, A. Cabeza, M. A. G. Aranda and K. D. Demadis, CrystEngComm, 2012, 14, 5385-5389.

7 Y. P. Zhu, T. Z. Ren and Z. Y. Yuan, Catal. Sci. Technol., 2015, 5, 4258-4279.

8 J. Goura and V. Chandrasekhar, Chem. Rev., 2015, 115, 6854-6965.

9 V. Chandrasekhar and P. Sasikumar, Dalton Trans., 2008, 6475-6480.

10 G. Karotsis, S. J. Teat, W. Wernsdorfer, S. Piligkos, S. J. Dalgarno and E. K. Brechin, Angew. Chem., Int. Ed., 2009, 48, 8285-8288.

11 Y. Z. Zheng, M. Evangelisti and R. E. P. Winpenny, Chem. Sci., 2011, 2, 99-102.

12 Y.-Z. Zheng, G.-J. Zhou, Z. Zheng and R. E. P. Winpenny, Chem. Soc. Rev., 2014, 43, 1462-1475.

13 V. Chandrasekhar, P. Sasikumar, R. Boomishankar and G. Anantharamian, Inorg. Chem., 2006, 45, 3344-3351.

14 V. Chandrasekhar, L. Nagarajan, R. Clerac, S. Ghosh and S. Verma, Inorg. Chem., 2008, 47, 1067-1073.

15 V. Baskar, M. Shanmugam, E. C. Sanudo, M. Shanmugam, D. Collison, E. J. L. McInnes, Q. Wei and R. E. P. Winpenny, Chem. Commun., 2007, 37-39.

16 E. K. Brechin, R. A. Coxall, A. Parkin, S. Parsons, P. A. Tasker and R. E. P. Winpenny, Angew. Chem., Int. Ed., 2001, 40, 2700-2703.

17 L. Batzdorf, F. Fischer, M. Wilke, K. J. Wenzel and F. Emmerling, Angew. Chem., Int. Ed., 2015, 54, 1799-1802.

18 M. Wilke, L. Batzdorf, F. Fischer, K. Rademann and F. Emmerling, RSC Adv., 2016, 6, 36011-36019.

19 T. Friscic, I. Halasz, P. J. Beldon, A. M. Belenguer, F. Adams, S. A. J. Kimber, V. Honkimaki and R. E. Dinnebier, Nat. Chem., 2013, 5, 66-73.
20 D. Gracin, V. Strukil, T. Friscic, I. Halasz and K. Uzarevic, Angew. Chem., Int. Ed., 2014, 53, 6193-6197.

21 A. Altomare, C. Cuocci, C. Giacovazzo, A. Moliterni, R. Rizzi, N. Corriero and A. Falcicchio, J. Appl. Crystallogr., 2013, 46, 1231-1235.

22 G. Nolze and W. Kraus, Powder Diffr., 1998, 13, 256-259.

23 BrukerAXS, Topas version 4.2, 2009.

24 H. Riesemeier, K. Ecker, W. Gorner, B. R. Muller, M. Radtke and M. Krumrey, X-Ray Spectrom., 2005, 34, 160163.

25 B. Ravel and M. Newville, J. Synchrotron Radiat., 2005, 12, 537-541.

26 O. Paris, C. H. Li, S. Siegel, G. Weseloh, F. Emmerling, H. Riesemeier, A. Erko and P. Fratzl, J. Appl. Crystallogr., 2007, 40, S466-S470.

27 A. P. Hammersley, S. O. Svensson, M. Hanfland, A. N. Fitch and D. Hausermann, High Pressure Res., 1996, 14, 235-248.

28 J. I. Langford and D. Louer, Rep. Prog. Phys., 1996, 59, 131234.

29 R. A. Coxall, S. G. Harris, D. K. Henderson, S. Parsons, P. A. Tasker and R. E. P. Winpenny, J. Chem. Soc., Dalton Trans., 2000, 2349-2356.

30 D. W. Lewis, A. R. Ruiz-Salvador, A. Gomez, L. M. Rodriguez-Albelo, F. X. Coudert, B. Slater, A. K. Cheetham and C. Mellot-Draznieks, CrystEngComm, 2009, 11, 2272-2276.

31 A. V. Trask, J. van de Streek, W. D. S. Motherwell and W. Jones, Cryst. Growth Des., 2005, 5, 2233-2241.

32 S. Karki, T. Friscic and W. Jones, CrystEngComm, 2009, 11, 470-481.

33 G. A. Bowmaker, Chem. Commun., 2013, 49, 334-348.

34 P. Balaz, M. Achimovicova, M. Balaz, P. Billik, Z. Cherkezova-Zheleva, J. M. Criado, F. Delogu, E. Dutkova, E. Gaffet, F. J. Gotor, R. Kumar, I. Mitov, T. Rojac, M. Senna, A. Streletskii and K. Wieczorek-Ciurowa, Chem. Soc. Rev., 2013, 42, 7571-7637.

35 X. Ma, W. Yuan, S. E. J. Bell and S. L. James, Chem. Commun., 2014, 2549-2558. 